\title{
Condition-Based Maintenance Modeling and Reliability Assessment for Multi-Component Systems with Structural Dependence under Extended Warranty
}

\author{
Rongcai Wang $\mathbb{D}^{\mathbb{D}}$, Zhonghua Cheng $\mathbb{D}$, Enzhi Dong, and Liqing Rong \\ Shijiazhuang Campus of Army Engineering University, Shijiazhuang 050003, China \\ Correspondence should be addressed to Zhonghua Cheng; asd3v36@163.com
}

Received 18 June 2021; Revised 12 July 2021; Accepted 26 July 2021; Published 6 August 2021

Academic Editor: Muhammad Javaid

Copyright ( 2021 Rongcai Wang et al. This is an open access article distributed under the Creative Commons Attribution License, which permits unrestricted use, distribution, and reproduction in any medium, provided the original work is properly cited.

\begin{abstract}
For engineering and production systems, due to the structural dependence between components, the disassembly operation caused by the replacement of components will affect the failure and degradation processes of other components in the system. In order to optimize the extended warranty (EW) cost of the multi-component system with structural dependence, this paper described the structural dependence and modeled the disassembly operation impact, and then the failure rate model of the component considering the impact of disassembly operation under EW was developed. Combined with the actual situation, a condition-based maintenance (CBM) strategy was employed to construct the EW cost model of the multi-component system with structural dependence. Monte Carlo simulation was proposed to determine the optimal EW cost of the system and the optimal periodic inspection interval of the CBM strategy. Finally, a numerical example of the planetary gear train of an automobile generator is introduced to demonstrate the feasibility and advantages of the proposed model in EW cost optimization and the analysis of disassembly operation impact on the optimal maintenance strategy.
\end{abstract}

\section{Introduction}

1.1. Motivation. Entering the twenty-first century, modern production technology has been greatly developed. Most durable consumer goods have a warranty policy (also called basic warranty). From the perspective of manufacturers and users, warranty policy has played an important role in improving the profitability of enterprises [1] and user satisfaction [2]. Generally speaking, warranty policies can be divided into basic warranty (BW) and extended warranty (EW). Blischke and Murthy [3] first introduced the concept and theoretical model of BW. There are two main reasons for providing a BW policy. For one thing, as a protection function, warranty is an obligation stipulated in the maintenance contract. During the warranty period, the manufacturer must repair or replace the failed products for the user free of charge [4]; for another thing, as a kind of promotion, a more attractive warranty policy can enable manufacturers to obtain higher user satisfaction and seize more market share $[5,6]$. BW, as an important part of product sales price [7], is usually provided by manufacturers. At the end of BW, manufacturers usually provide users with the option to purchase EW services [8]. Actually, users can choose whether to buy EW at the end of BW [9]. In recent years, EW has been widely concerned by manufacturers and customers [10]. EW refers to the extra warranty period provided by the manufacturer for its products at the end of BW, which is an extension of BW. EW, as an optional warranty policy, has aroused widespread concern in the industry and academia [11]. Unlike BW policy, which is free for consumers and bundled with products, EW is an optional contract, which usually provides extra protection for customers after BW expires and must be purchased separately at extra cost [12]. Existing EW research and market cases show that EW plays an increasingly important role for manufacturers and users [13]. More and more manufacturers tend to provide extra insurance for their products in the form of EW [14]. For manufacturers, EW has become a 
rich source of profits [15], which means that EW has brought some manufacturers a profit margin of $44 \%$ to $77 \%$; in addition, a considerable number of users purchase EW services to reduce the economic burden caused by product failures [8]. Although EW will bring extra costs to users, considering that the structure and functions of modern products are becoming more and more complex and expensive to maintain, more and more users tend to purchase EW services [16]. In other words, EW alleviates consumers' worries about product failure after BW expires [9]. As far as manufacturers are concerned, EW also provides opportunities to establish and maintain relationships with consumers after BW ends. For manufacturers and users, providing or purchasing EW services requires extra cost. Therefore, the pricing of EW has become an urgent problem to be solved. However, few studies have focused on this field [17]. Through literature research, it is found that the key factor affecting the price of EW is the cost of EW. Different repair strategies have different EW costs [18]. Therefore, it is very important for manufacturers to balance sales and costs. Warranty policies and maintenance plans should be carefully considered. Modern engineering systems and manufacturing systems usually consist of several interdependent components or subsystems [19]. From the perspective of cost, reliability, and availability, the maintenance activities of these systems play a key role in their effective usage. In addition, reliability is an important key performance indicator for manufacturing systems [20-22]. The accurate assessment of system reliability must prove its functionality, efficiency, and safety [23]. However, due to the complexity of the system, it is difficult to model maintenance optimization and evaluate the reliability of the failure process within the scope of production requirements; that is, the various components of the multicomponent system are interdependent in some form. In a multi-component system, there are usually three forms of dependence between components: economic dependence, stochastic dependence, and structural dependence [24]. Economic dependence means that, compared with the individual maintenance of components, the combined maintenance of multiple components can reduce (positive economic dependence) or increase (negative economic dependence) maintenance costs [25]. Random dependence means that the state of the component will affect the failure process of other components in the system [26]. Finally, when the components form a structurally connected system, structural dependence occurs. Therefore, the disassembly of the component requires the removal of other blocking components from the system. Therefore, these disassembled components may be damaged [27], which will affect their failure process. In a multi-component system, the dependence between components not only brings challenges to the realization of maintenance operations but also brings challenges to the modeling of component failure processes. In fact, many existing studies assume that the components in the system are independent, so the maintenance actions and failure processes of each component are modeled separately $[28,29]$. This is not always true in practice.
Nevertheless, the dependence between components exists not only in the operation process but also in the maintenance process. For example, in a multi-component system with structural dependence, the disassembly operation of the component to be repaired may affect the failure process of the disassembled component. Even from a practical point of view, structural dependence widely exists in various engineering and manufacturing systems, but the impact of structural dependence has not been considered and studied in component degradation and failure modeling. Therefore, the modeling and application of the multicomponent system with structural dependence considering the impact of disassembly operation has important research value and necessity.

1.2. Contributions of This Work. However, in the above studies, there is no literature to carry out EW decisionmaking research for multi-component systems structural dependence considering the impact of disassembly operation. In traditional maintenance models, most of the modeling studies on EW assume that the components are independent to each other in the system. Model construction and solution are less difficult, but there is a big error between the maintenance process and the actual situation. Therefore, in EW studies, simply treating the components in the system as independent of each other is not in line with the actual situation. It is necessary to consider the structural dependence between the components and the impact of disassembly operation to make the maintenance process more consistent with the actual situation. This paper intends to fill this gap.

In the current study, we will focus on the structural dependence among the components in the above systems. In the literature, disassembly operations can be divided into three types: nondestructive disassembly, semidestructive disassembly, and destructive disassembly [19]. However, due to the limitation of maintenance resources and technical conditions, whether nondestructive, semidestructive, or destructive disassembly operations are adopted, the failure process of the disassembled components may be affected. However, the previous research seldom involves the impact of disassembly operation due to the structural dependence between components on maintenance optimization modeling and failure process [30]. In the framework of multicomponent system maintenance optimization, maintenance strategies can generally be divided into two categories: timebased maintenance (TBM) and condition-based maintenance (CBM) [31]. At present, the existing TBM and CBM modeling research studies mostly focus on single-component systems [32, 33]. However, there are few research studies on multi-component systems. In addition, the existing research studies on multi-component systems mainly focus on TBM [34]. Although CBM is more economical than TBM $[35,36], \mathrm{CBM}$ of multi-component systems has not been fully developed. CBM has been introduced and become an important strategy in the framework of maintenance optimization [26], which means that preventive maintenance plan is based on the inspection 
status of the system. This is a very suitable maintenance strategy, which can use the available information of system status to optimize maintenance decisions [37]. Keizer [27] reviewed and summarized the related theoretical methods, practical applications, and the latest progress of CBM strategy in multidependent component systems. Therefore, the optimization modeling of multi-component systems with structural dependence is worth studying deeply.

Therefore, the rest of this paper is organized as follows: Section 2 first describes the model assumptions and notations used in the paper. Next, to construct the failure rate model of the component under EW, the description of disassembly operation and the modeling of disassembly operation impact are presented under the logical framework in Section 2. Then, we develop a CBM strategy for the multicomponent system based on periodic inspection and reliability threshold. On this basis, the failure rate model and EW cost model of the multi-component system considering the impact of disassembly operation under EW are proposed in Section 3. A numerical example is then given in Section 4 to illustrate the impact of disassembly operation and obtain the optimal maintenance strategy with the lowest EW cost of the multi-component system with structural dependence under EW using the Monte Carlo simulation. Finally, the conclusions are summarized in Section 5.

\section{Analyzing and Modeling the Impact of Structural Dependence}

2.1. Model Assumptions. To facilitate the research, the system modeling is based on the following assumptions:

(1) In the BW period, due to the low failure rate, only the minimal maintenance after failures is carried out, and the structural dependence can be ignored because minimal maintenance does not require disassembly operation

(2) Only the replacement actions of the component will cause the occurrence of the disassembly operation

(3) The minimal maintenance does not change the degradation, reliability, and failure rate of the component, and the minimal maintenance time is ignored

(4) The preventive maintenance and corrective maintenance during the EW period are the perfect maintenance, and the components will be restored to the state of "as good as new" after maintenance

(5) The periodic inspection whose time can be ignored is perfect inspection, and the failures of components will be discovered in time

(6) The degradation parameters are not affected by the disassembly operation, and they are fixed values

2.2. System Description and Modeling. Under the EW policy, this paper studies a multi-component system with structural dependence. The BW period and EW period are $[0, W]$ and $\left[W, W_{e}\right]$ and start from $t=0$ and $t=W$, respectively. In the framework of reliability and maintenance, it is assumed that the multi-component system is composed of $n, n \geq 1$ components in series. Therefore, for whatever reason (such as failures or maintenance activities), the shutdown of each component will lead to the shutdown of the system.

The hierarchical structure between components in the system can be represented by the directed graph [38]. Furthermore, the failure rate function of component $i(i=$ $1,2,3, \ldots, n)$ can be described by the Weibull proportional hazard model [23]:

$$
\lambda_{i}\left(t, X_{i}(t)\right)=\lambda_{i}^{0}(t) \varphi\left(X_{i}(t)\right),
$$

where $\lambda_{i}^{0}(t)=\alpha_{i} t^{\alpha_{i}-1} / \beta_{i}^{\alpha_{i}}$ is the Weibull hazard rate function with shape parameter $\alpha_{i}$ and scale parameter $\beta_{i}$, respectively; $\varphi\left(X_{i}(t)\right)=\tau_{i} X_{i}(t), X_{i}(t)$ is a degradation function of component $i$, and $\tau_{i}$ is regression coefficient, which is used to quantify the impact of degradation on the failure rate of component $i$. In addition, it is generally assumed that $X_{i}(t)$ follows a certain linear relationship, that is, $X_{i}(t)=\varepsilon_{i}+\gamma_{i} t+\kappa_{i} B(t) . X_{i}(t)$ is the degradation process driven by $B(t)$, and $\varepsilon_{i}, \gamma_{i}$, and $\kappa_{i}$ are the initial degradation amount, degradation rate, and diffusion coefficient of component $i$, respectively. $B(t)$ denotes the standard Brownian motion and obey a distribution of $B(t) \sim N(0, t)$.

The Weibull proportional hazard model has been widely studied and successfully applied to practical engineering systems [39]. These parameters are known or estimated based on historical data and are used to model the impact of disassembly operation, reliability assessment, and maintenance optimization. The reliability of component $i$ represents the probability that it is still in operation at time $t$, which can be derived as follows:

$$
R_{i}(t)=\exp \left[-\int_{0}^{t} \lambda_{i}\left(x, X_{i}(x)\right) \mathrm{d} x\right] .
$$

For the series multi-component system, the reliability of the system at time $t$ is as follows:

$$
R_{s}(t)=\prod_{i=1}^{n} R_{i}(t) .
$$

\subsection{Disassembly Operation Description and Modeling the} Disassembly Operation Impact. Disassembly operation is the process of separating the components to be repaired from the system [39]. The components are connected to form a whole structure. The separation of failed components is the process of breaking the connection between components through disassembly operation. In the process of disassembly operation, the degradation of components will be affected. These damages will increase the failure risk of components and reduce the reliability and performance of components. If the effect of disassembly operation on the degradation process of components is ignored, the failure risk of components and systems will be underestimated.

In order to clearly show the connection relationship between components, the connection matrix is used to represent the structure of the system. The connection matrix of the system, $M_{s}=\left[e_{i j}\right]_{n \times n}$, is a square matrix of order $n$, 
indicating whether there is a structural connection between component $i$ and component $j$. When the value of $e_{i j}$ is 1 , the connection exists; if $e_{i j}$ is equal to 0 , it indicates that there is no connection between the two components [40]. At the same time, we use the directed graph [30] to represent the disassembly sequence of other components to be disassembled when repairing a given component. Figure 1 shows the gearbox system of a certain type of automobile transmission systems.

Many scholars have studied the method of finding the optimal disassembly path $[41,42]$. This paper does not do specific research on this topic. It is assumed that the disassembly path for each component is predefined and limited by the previous design. Therefore, in Figure 1, according to the actual situation of the gearbox system, the directed graph of the gearbox system can be obtained as shown in Figure 2 .

According to the definition of connection matrix, by analyzing the structural diagram of the gearbox system, the connection matrix can be obtained as follows:

$$
M_{s}=\left(\begin{array}{llll}
0 & 1 & 0 & 0 \\
1 & 0 & 1 & 1 \\
0 & 1 & 0 & 0 \\
0 & 1 & 0 & 0
\end{array}\right) .
$$

Among them, node 0 represents the whole gearbox system, and the other four nodes 1,2,3, and 4 represent the single components of the gearbox system, respectively. The line connecting the upper and lower nodes indicates that the upper node needs to be disassembled before the lower node is removed. The arrow between nodes on the same layer refers to the disassembly sequence between nodes. It is assumed that when the connection $(i, j)$ between component $i$ and component $j$ is disassembled, a certain amount of damage $\zeta_{i j}$ will be caused to the degradation level of component $i$. Similarly, $\zeta_{j i}$ represents the damage to component $j$ caused by the disassembly operation. $\zeta_{i j}$ is used for modeling the disassembly impact, which is mainly affected by the following factors:

(1) The connection strength $M_{s}^{\Theta}=\left[\psi_{i j}\right]_{n \times n}$ between components, $\psi_{i j} \geq 0$, indicates the strength of the connection between component $i$ and component $j$. The greater the strength of the connection, the greater the impact of the disassembly operation on the degradation level of the components. The value of $M_{s}^{\Theta}$ is determined and can be obtained in the design phase of the system. As shown in Figure 1, according to the clearance between the bearing and the shaft, the friction between the bearing and the shaft can be calculated to represent the connection strength between the two components:

$$
M_{s}^{\Theta}=\left(\begin{array}{llll}
0 & 5 & 0 & 0 \\
5 & 0 & 2 & 5 \\
0 & 2 & 0 & 0 \\
0 & 5 & 0 & 0
\end{array}\right) .
$$

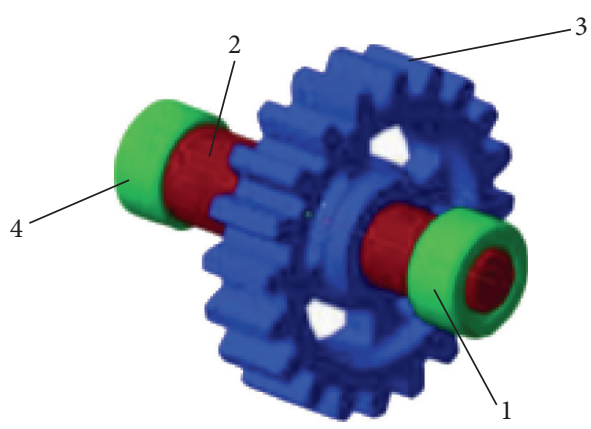

FIgURE 1: The structural diagram of the gearbox system.

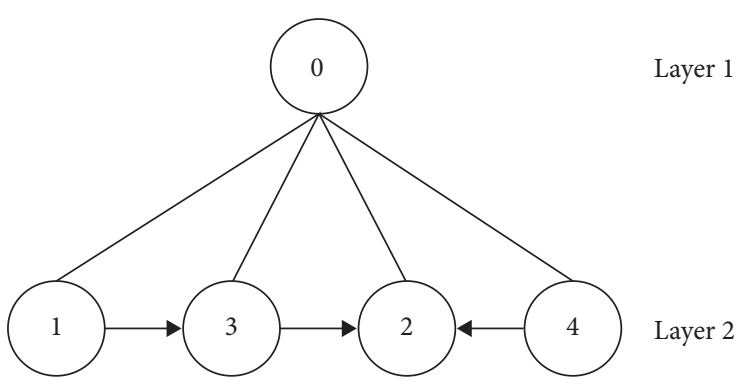

FIgURE 2: The directed graph of the gearbox system.

(2) The physical properties of the component $i$ expressed by $p_{i}\left(p_{i} \geq 0\right)$. For example, components made of highstrength materials are less susceptible to disassembly operations than components made of low-strength materials. The physical properties of components can be estimated based on historical data, life tests, etc.

(3) Technical ability of the maintenance personnel and maintenance tools. For example, using the mechanical process to disassemble the bearings is more harmful than the hydraulic process; in addition, the technical ability of the maintenance personnel will also affect the damage degree of components caused by disassembly operation $[43,44]$. Therefore, combining the above two factors, the adjustment factor $\phi_{i j}$ is applied to reflect the influence of the technical ability of the maintenance personnel and the maintenance tools when dismantling the connection $(i, j)$. The adjustment factor $\phi_{i j}$ can be regarded as the quality of disassembly operation, and it is very difficult to estimate accurately. Therefore, we assume that $\phi_{i j}$ is a random variable subject to a normal distribution, and $\mu_{\phi_{i j}}$ and $\sigma_{\phi_{i j}}$ are the mean and standard deviation of the normal distribution, which represent the impact of maintenance tools and the technical ability of the maintenance personnel, respectively. The probability density function of the normal distribution can be written as follows:

$$
f_{\mu_{\phi_{i j}}, \sigma_{\phi_{i j}}}(x)=\frac{1}{\sqrt{2 \pi} \sigma_{\phi_{i j}}} e^{-(1 / 2)\left(x-\mu_{\phi_{i j}} / \sigma_{\phi_{i j}}\right)^{2}} .
$$


To sum up, referring to the linear model constructed by Thompson [45] when calculating the amount of wear due to friction, because the physical meaning is similar, we construct a linear form about $\psi_{i j}$, $p_{i}$, and $\phi_{i j}$ to express the impact of disassembly operation, which can be expressed as follows:

$$
\zeta_{i j}=\psi_{i j} \cdot p_{i} \cdot \phi_{i j}
$$

It can be seen that $\zeta_{i j}$ also obeys the normal distribution with mean $\mu_{\zeta_{i j}}=\psi_{i j} \cdot p_{i} \cdot \mu_{\phi_{i j}}$ and variance $\sigma_{\zeta_{i j}}^{2}=\left(p_{i} \psi_{i j}\right)^{2}$ $\sigma_{\phi_{i j}}^{2}$, then

$$
f_{\mu_{\zeta_{i j},} \sigma_{\zeta_{i j}}}(x)=\frac{1}{\sqrt{2 \pi} \sigma_{\zeta_{i j}}} e^{-(1 / 2)\left(\left(x-\mu_{\zeta_{i j}}\right) / \sigma_{\zeta_{i j}}\right)^{2}} .
$$

In the process of removing the components that need to be repaired from the system, due to the structural dependence, the connection between other components in the disassembly path of the failed or to be repaired components should also be removed. The disassembly path of the components can be represented by the disassembly matrix, and it is assumed that the disassembly matrix has been determined. Let the disassembly path of component $r$ be represented by disassembly matrix $D^{r}=\left[D_{i j}^{r}\right]$. When the connection $(i, j)$ between component $i$ and component $j$ is on the disassembly path of component $r$, then $D_{i j}^{r}=1$; otherwise, $D_{i j}^{r}=0$. For example, in Figure 1, the disassembly matrix of component 3 is as follows:

$$
D^{3}=\left(\begin{array}{llll}
0 & 1 & 0 & 0 \\
1 & 0 & 1 & 0 \\
0 & 1 & 0 & 0 \\
0 & 0 & 0 & 0
\end{array}\right) .
$$

Therefore, the impact of disassembly operation on the degradation level of component $i$ can be expressed as follows:

$$
L_{i r}=\sum_{j=1}^{n} \zeta_{i j} D_{i j}^{r}
$$

When repairing a group of components $Q^{h}$, $\left(Q^{h} \neq \varnothing\right) \cap\left(i \notin Q^{h}\right), h$ means the $h$-th maintenance action for $Q^{h}$, and the disassembly paths of different components intersect. The disassembly path for a group of components $Q^{h} \quad$ can be defined as $D^{Q^{h}}=D^{j} \cup D^{k} \cup \ldots \cup D^{v}$, $j, k, \ldots, v \in Q^{h}$. Therefore, it can be concluded that the impact of disassembly operation on the degradation level of component $i$ is as follows:

$$
L_{i \mathrm{Q}^{h}}=\sum_{j=1}^{n} \zeta_{i j} D_{i j}^{\mathrm{Q}^{h}}
$$

Based on the above analysis, it is assumed that the directed graph of a three-component system structure is shown in Figure 3, the maintenance activity is perfect maintenance, and the components can be restored as good as new. Figure 4 illustrates the degradation law of components in the EW period due to the structural dependence between components.

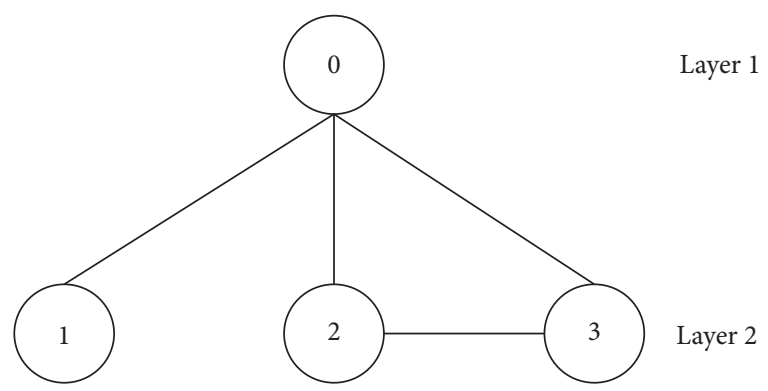

FIGURE 3: The directed graph of the three-component system.

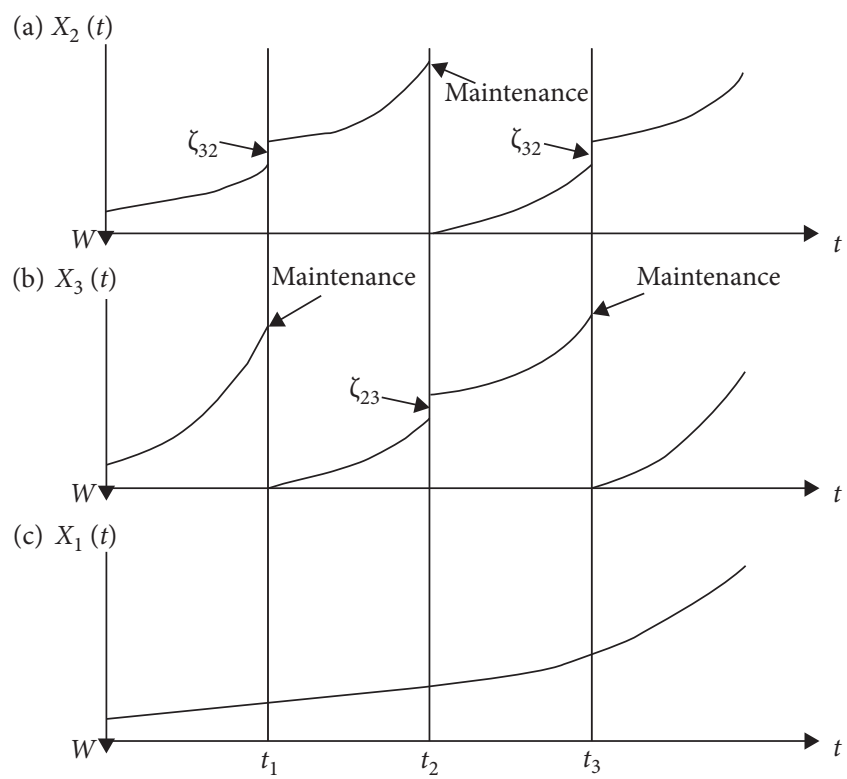

FIGURE 4: Change graph of the component degradation function considering the impact of disassembly operation.

\section{Maintenance Strategy}

3.1. CBM Strategy Description. Taking into account the structural dependence between the components in the system, a CBM strategy is adopted to optimize the system EW cost, thereby reducing the system EW price.

During the EW period, each component in the system is inspected regularly with an interval $\rho$, and the moment of the $v$-th inspection of the component is $T_{v}=v \rho, v=1,2,3, \ldots$, so it is necessary to evaluate and calculate the degradation level of the components in operation during each inspection. The single inspection cost of component $i$ is $C_{\text {is }}$, and the specific maintenance strategy is discussed in two cases:

(1) If component $i$ fails in the inspection interval $\left(T_{v-1}, T_{v}\right)$, the minimal repair will be implemented on component $i$ immediately

(2) If component $i$ is still running at the inspection moment $T_{v}$, further decision should be made according to the prediction of the component reliability

If the reliability $R_{i}\left(T_{v}\right)$ of component $i$ is less than the failure threshold $R_{f}$, component $i$ will be replaced at $T_{v}$. 
If the reliability $R_{i}\left(T_{v+1} \mid T_{v}\right)$ of component $i$ at the next inspection moment $T_{v+1}$ is lower than its preventive maintenance threshold $R_{p}$, the preventive replacement will be performed on component $i$ at $T_{v}$.

If the failure replacement or preventive replacement is performed on a group of components $Q^{h}$ at $T_{v}$, and the reliability $R_{i}\left(T_{v+1} \mid T_{v}\right)$ of component $i\left(i \notin Q^{h}\right)$ at the next inspection moment $T_{v+1}$ is lower than its opportunistic maintenance threshold $R_{b}\left(R_{p} \leq R_{b}<1\right)$, then the opportunistic preventive replacement will be performed on component $i$.

The CBM strategy proposed in this paper is shown in Figure 5.

The characteristic of minimal maintenance is a nonhomogeneous Poisson process (NHPP). The expected minimal repair number of the system in $[0, t]$ is about

$$
E[N(t)]=\int_{0}^{t} \lambda(s) \mathrm{d} s
$$

3.2. Failure Rate Modeling considering the Impact of Disassembly Operation under EW. For each component in the system, the degradation function is composed of two parts, including its continuous degradation with time and the degradation caused by disassembly operation.

According to the inspection interval, the number of inspection for the system during the EW period is

$$
v_{e}=\operatorname{int}\left[\frac{W_{e}-W}{\rho}\right] \text {. }
$$

In equation (13), "int" means rounding down.

During the EW period, the degradation function of component $i$ can be expressed as follows:

$$
X_{\mathrm{Li}}(t)= \begin{cases}X_{i}(t)+\sum_{h=0}^{\mathrm{EN}(t-W)} L_{i \mathrm{Q}^{h}}, & t \in\left[W, t_{f}\right], \\ X_{i}(t)+\sum_{h=0}^{\mathrm{EN}(t)} L_{i \mathrm{Q}^{h},} & t \in\left[0, v_{d} \rho\right], \\ X_{i}(t)+\sum_{h=0}^{\mathrm{EN}(t)} L_{i \mathrm{Q}^{h},} & t \in\left[0, v_{c} \rho+W_{e}-v_{e} \rho\right],\end{cases}
$$

where $\mathrm{EN}\left(t_{1}\right)$ is the average number of maintenance actions for a group of components $Q^{h}$ in $\left[0, t_{1}\right] ; t_{f}$ is the first replacement moment of component $i$ in the EW period, $t_{f}=W+v \rho, v=1,2,3, \ldots, v_{e} ; v_{d} \rho$ is the interval between the first replacement moment and the next replacement moment of component $i$ in the EW period, $v_{d}=1,2,3, \ldots, v_{e}-1 ; v_{c} \rho+W_{e}-v_{e} \rho$, which represents the interval between the last replacement moment of component $i$ during the EW period and the EW deadline, $v_{c}=0,1,2, \ldots, v_{e}-1$. Therefore, the failure rate function of component $i$ in the EW period can be deduced as follows:

$$
\lambda_{i}\left(t, X_{\mathrm{Li}}(t)\right)=\lambda_{i}^{0}(t) \varphi\left(X_{\mathrm{Li}}(t)\right)=\lambda_{i}^{0}(t) \tau_{i} X_{\mathrm{Li}}(t) .
$$

According to equation (14), it can be concluded that

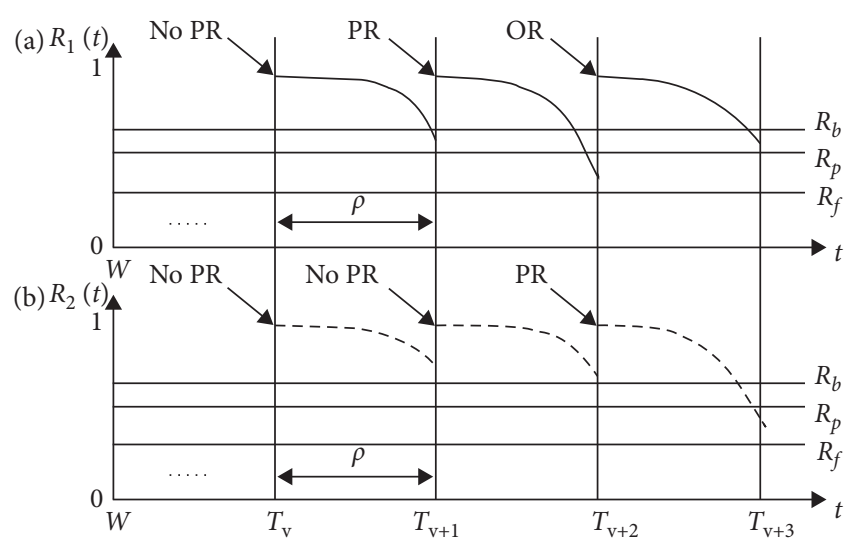

FIGURE 5: CBM strategy diagram. PR represents preventive replacement, while OR denotes opportunistic preventive replacement.

$$
\lambda_{i}\left(t, X_{\mathrm{Li}}(t)\right)= \begin{cases}\lambda_{i}^{0}(t) \tau_{i}\left[X_{i}(t)+\sum_{h=0}^{\mathrm{EN}(t-W)} L_{i Q^{h}}\right], & t \in\left[W, t_{f}\right], \\ \lambda_{i}^{0}(t) \tau_{i}\left[X_{i}(t)+\sum_{h=0}^{\mathrm{EN}(t)} L_{i Q^{h}}\right], & t \in\left[0, v_{d} \rho\right], \\ \lambda_{i}^{0}(t) \tau_{i}\left[X_{i}(t)+\sum_{h=0}^{\mathrm{EN}(t)} L_{i Q^{h}}\right], & t \in\left[0, v_{c} \rho+W_{e}-v_{e} \rho\right] .\end{cases}
$$

Then, the minimal maintenance number of component $i$ during the EW period can be derived as follows:

$$
\begin{aligned}
E_{i}[N(t)]= & N_{1}(t)+N_{2}(t)+N_{3}(t), \\
N_{1}(t)= & \int_{W}^{t_{f}} \lambda_{i}^{0}(t) \tau_{i}\left[X_{i}(t)+\sum_{h=0}^{\mathrm{EN}(t-W)} L_{i Q^{h}}\right] \mathrm{d} t, \quad t \in\left[W, t_{f}\right], \\
N_{2}(t)= & \sum \int_{0}^{v_{d} \rho} \lambda_{i}^{0}(t) \tau_{i}\left[X_{i}(t)+\sum_{h=0}^{\mathrm{EN}(t)} L_{i Q^{h}}\right] \mathrm{d} t, \quad t \in\left[0, v_{d} \rho\right], \\
N_{3}(t)= & \int_{0}^{v_{c} \rho+W_{e}-v_{e} \rho} \lambda_{i}^{0}(t) \tau_{i} \\
& {\left[X_{i}(t)+\sum_{h=0}^{\mathrm{EN}(t)} L_{i Q^{h}}\right] \mathrm{d} t, \quad t \in\left[0, v_{c} \rho+W_{e}-v_{e} \rho\right], }
\end{aligned}
$$

where the expression of $N_{2}(t)$ is the sum of multiple integrals and the number of integrals is uncertain changing with the length of EW, which represents the minimal maintenance number of component $i$ between the first and last replacement.

3.3. Reliability Assessment of Components considering the Disassembly Operation Impact. If component $i$ is still in operation at the inspection moment $T_{v}$, the reliability of component $i$ at the next inspection moment $T_{v+1}$ is as follows:

$$
R_{i}\left(T_{v+1} \mid T_{v}\right)=\exp \left[-\int_{T_{v}}^{T_{v+1}} \lambda_{i}\left(t, X_{i}(t)\right) \mathrm{d} t\right] .
$$


When the failure replacement or preventive replacement of a group of components $Q^{h}$ is carried out at the inspection moment $T_{v}$, considering the impact of the disassembly operation of $Q^{h}$ on the degradation level of component $i$, the reliability of component $i$ at the next inspection moment $T_{v+1}$ can be obtained as follows:

$$
R_{i}\left(T_{v+1} \mid T_{v}\right)=\exp \left[-\tau_{i} \int_{T_{v}}^{T_{v+1}} \lambda_{i}^{0}(t)\left[X_{i}(t)+L_{i Q^{h}}\right] \mathrm{d} t\right] .
$$

3.4. EW Cost and Maintenance Optimization of the MultiComponent System with Structural Dependence. During the EW period, the EW cost of component $i$ can be divided into three parts: preventive maintenance cost $C_{\mathrm{pi}}$, corrective maintenance cost $C_{\mathrm{fi}}$, and minimal maintenance cost $C_{\mathrm{mi}}$. The following will be analyzed separately.

3.4.1. Preventive Maintenance Cost $C_{p i}$. For component $i$, the single preventive maintenance cost $C_{\mathrm{pi}}$ includes single preventive replacement cost $C_{\text {pri }}$ and the downtime loss cost $C_{\mathrm{pti}}$, which is $C_{\mathrm{pi}}=C_{\mathrm{pri}}+C_{\mathrm{pti}}$. The downtime includes single replacement time $T_{\text {pri }}$ and single disassembly operation time $T_{\mathrm{di}}$. The shutdown loss per unit time is $C_{\mathrm{pd}}$, then

$$
C_{\text {pti }}=\left(T_{\text {pri }}+T_{\text {di }}\right) C_{\text {pd }} \text {. }
$$

According to the disassembly path and disassembly matrix, the disassembly time of component $i$ can be calculated as follows:

$$
T_{\mathrm{di}}=\frac{1}{2} \sum_{a=1}^{n} \sum_{b=1}^{n} T_{a b} D_{a b}^{i} .
$$

where $T_{a b}$ is the time taken to disassemble the connection $(a, b)$. Similarly, the disassembly time of a group of components $Q^{h}$ is as follows:

$$
T_{d Q^{h}}=\frac{1}{2} \sum_{a=1}^{n} \sum_{b=1}^{n} T_{a b} D_{a b}^{Q^{h}} .
$$

Therefore, for a group of components $Q^{h}$, the downtime caused by a preventive replacement is as follows:

$$
T_{d}^{Q^{h}}=T_{d Q^{h}}+\sum_{i \in Q^{h}} T_{\text {pri }} .
$$

3.4.2. Corrective Maintenance Cost $C_{f i}$. During the EW period, the single corrective maintenance cost of component $i$ includes single failure replacement $\operatorname{cost} C_{\text {fri }}$ and the downtime loss cost $C_{\mathrm{fti}}$, namely $C_{\mathrm{fti}}$. The downtime includes single replacement time $T_{\text {fri }}$ and single disassembly operation time $T_{\mathrm{di}}$, and the shutdown loss per unit time is $C_{\mathrm{pd}}$, then

$$
C_{\text {fti }}=\left(T_{\text {fri }}+T_{\mathrm{di}}\right) C_{\mathrm{pd}},
$$

where the preventive replacement time is equal to the failure replacement time, that is, $T_{\text {pri }}=T_{\text {fri }}=T_{\text {ri }}$. Therefore, for a group of components $Q^{h}$, the downtime caused by one failure replacement is

$$
T_{d}^{\mathrm{Q}^{h}}=T_{d \mathrm{Q}^{h}}+\sum_{i \in \mathrm{Q}^{h}} T_{\text {fri }}
$$

In summary, the system EW cost can be obtained as follows:

$$
\operatorname{EC}\left(\rho, W_{e}\right)=\sum_{i=1}^{n} \sum C_{\mathrm{pi}}+\sum_{i=1}^{n} \sum C_{\mathrm{fi}}+E_{i}[N(t)] C_{\mathrm{mi}} .
$$

In equation (26), $\sum C_{\mathrm{pi}}$ and $\sum C_{\mathrm{fi}}$ represent the total preventive maintenance cost and total corrective maintenance cost of component $i$ during the EW period, respectively. In the above model, the decision variables are $\rho$ and $W_{e}$. In order to obtain the minimal EW cost, the above decision variables need to be optimized. By minimizing the system EW cost, the best inspection interval $\rho^{*}$, the optimal EW cost EC $\left(\rho^{*}, W_{e}\right)$, and the lowest EW price $P\left(\rho^{*}, W_{e}\right)$ in different EW periods can be obtained.

\section{Numerical Example}

4.1. Problem Description. Planetary gear train is an advanced gear transmission mechanism, which is mainly composed of planetary gear, center gear, and planetary carrier. It is widely used in the mechanical equipment of national defense, wind power, construction industry, and other departments. Taking the planetary gear train of an automobile generator as an example, the impact of disassembly operation on the reliability and maintenance optimization of the planetary gear train is explained in detail. The three-dimensional model of the planetary gear train is shown in Figure 6.

In Figure 6, 1, 2, and 3 represent the center gear, planetary gear, and planetary carrier, respectively. Planetary gear train is a system with structural dependence, and the directed graph of the system is shown in Figure 7.

By analyzing the system mechanism of the planetary gear train, the connection matrix can be obtained as follows:

$$
M_{s}^{\Theta}=\left(\begin{array}{ccc}
0 & 0.8 & 0 \\
0.8 & 0 & 1.1 \\
0 & 1.1 & 0
\end{array}\right) .
$$

Similarly, we can get the disassembly matrix of the planetary gear train as follows:

$$
\begin{aligned}
D^{1} & =\left(\begin{array}{lll}
0 & 1 & 0 \\
1 & 0 & 0 \\
0 & 0 & 0
\end{array}\right), \\
D^{2} & =\left(\begin{array}{lll}
0 & 1 & 0 \\
1 & 0 & 1 \\
0 & 1 & 0
\end{array}\right), \\
D^{3} & =\left(\begin{array}{lll}
0 & 0 & 0 \\
0 & 0 & 1 \\
0 & 1 & 0
\end{array}\right) .
\end{aligned}
$$

The failure rate and degradation parameters of each component of the planetary gear train are shown in Table 1 . 


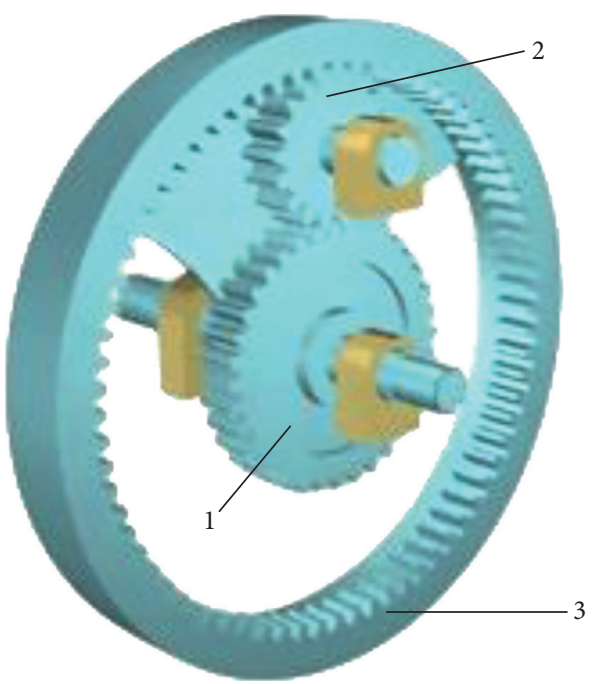

FIgURE 6: Three-dimensional model of the planetary gear train.

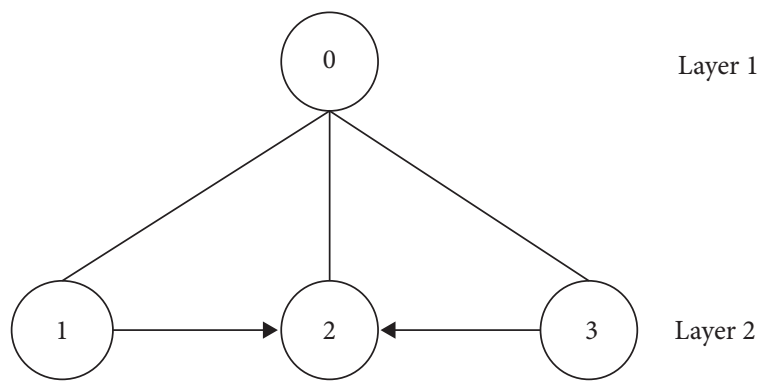

FIgURE 7: The directed graph of the planetary gear train.

TABLE 1: System parameters.

\begin{tabular}{lccccccc}
\hline Component & $\alpha_{i}$ & $\beta_{i}$ (months) & $\tau_{i}$ & $\varepsilon_{i}$ & $\gamma_{i}$ & $\kappa_{i}$ & $p_{i}$ \\
\hline 1 & 3 & 12 & 0.25 & 0 & 0.03 & 0.02 & 1.8 \\
2 & 2 & 50 & 0.05 & 0 & 0.04 & 0.02 & 2.5 \\
3 & 4 & 20 & 0.2 & 0 & 0.01 & 0.01 & 1.6 \\
\hline
\end{tabular}

Furthermore, according to historical data analysis, $R_{f}=0.3, R_{p}=0.65$, and $R_{b}=0.75$. The maintenance cost parameters of the system are shown in Table 2. The unit of all maintenance cost parameters is set to $\mathrm{CNY}$.

In Table 2, the unit of $C_{\mathrm{pd}}$ is CNY/day. In addition, the disassembly time of each connection $(a, b)$ and the mean $\mu_{\phi_{i j}}$ and standard deviation $\sigma_{\phi_{i j}}$ of the adjustment factor $\phi_{i j}$ in the planetary gear train are shown as follows:

$$
\begin{aligned}
\mu_{\phi_{i j}} & =\left(\begin{array}{ccc}
0 & 1.1 & 0 \\
1.1 & 0 & 1.2 \\
0 & 1.2 & 0
\end{array}\right), \\
\sigma_{\phi_{i j}} & =\left(\begin{array}{ccc}
0 & 0.1 & 0 \\
0.1 & 0 & 0.2 \\
0 & 0.2 & 0
\end{array}\right), \\
T_{a b} & =\left(\begin{array}{lll}
0 & 1 & 0 \\
1 & 0 & 2 \\
0 & 2 & 0
\end{array}\right) .
\end{aligned}
$$

TABLE 2: Maintenance cost parameters.

\begin{tabular}{lcccccc}
\hline Component & $C_{\text {pri }}$ & $C_{\text {fri }}$ & $C_{\mathrm{mi}}$ & $C_{\mathrm{is}}$ & $C_{\mathrm{pd}}$ (days) & $T_{\mathrm{ri}}$ (hours) \\
\hline 1 & 700 & 850 & 60 & 150 & 1000 & 4 \\
2 & 550 & 700 & 50 & 200 & 1000 & 5 \\
3 & 600 & 760 & 75 & 300 & 1000 & 2 \\
\hline
\end{tabular}

It is assumed that the BW period of the planetary gear system is $W=2$ years; besides, one year and one month are calculated as 360 days and 30 days, respectively.

4.2. The Optimal Maintenance Strategy. According to the above analysis and combined with relevant parameters, for the complex nonlinear model in this paper, Monte Carlo simulation is herein applied to figure out the optimal values of the decision variables $\left(\rho, W_{e}\right)$. The flowchart of Monte Carlo simulation is presented in Figure 8. In the above model, EW cost will change with the change of periodic inspection interval $\rho$ and the EW deadline $W_{e}$. Suppose the value range of the periodic inspection interval $\rho$ is $\left[36,336\right.$ days], and the value range of EW deadline $W_{e}$ is $[3,10$ years], whose change steps are all 30 days.

On the basis of the above data assumption, we can get the change law of EW cost of the planetary gear train with different inspection intervals $\rho$ and EW deadline $W_{e}$, as shown in Figure 9. The jumping points on the surface are caused by different inspection intervals.

It is demonstrated in Figure 9 that system EW cost is influenced by the two variables $\rho$ and $W_{e}$. Moreover, there is a minimal point for each curve that system EW cost changes with $\rho$. That means we can obtain the optimal periodic inspection intervals. At the same time, if $\rho$ is fixed, the system EW cost will always increase as $W_{e}$ grows. This is in line with the law that the failure rate of each component of the system will continue to increase over time and the system maintenance costs increase accordingly.

In order to facilitate the analysis and research on the change law of EW cost, the three-dimensional graph of EW cost is fixed at $W_{e}=3420,1440$ days and $\rho=246,96$ days for dimensionality reduction analysis, as shown in Figure 10.

As can be seen from Figure 10 that when the periodic inspection interval is fixed, the system EW cost increases with the increase of EW period; when the EW period is determined, there is an optimal periodic inspection interval to minimize the system EW cost.

Generally speaking, EW is a special commodity with a certain price. Manufacturers need to obtain a certain profit to provide the EW services. Consequently, it is usually necessary to consider two factors to determine the EW price, that is, EW cost and the manufacturer's profit demand. In view of this, the EW price model of the multi-component system with structural dependence can be expressed as

$$
P\left(t_{a}, t_{b}\right)=\mathrm{EC}\left(t_{a}, t_{b}\right)+\psi\left(t_{b}-t_{a}\right)
$$

where $t_{a}$ and $t_{b}$ are the beginning and end time of EW, respectively; $\mathrm{EC}\left(t_{a}, t_{b}\right)$ represents $\mathrm{EW}$ cost during $\left(t_{a}, t_{b}\right) ; \psi$ denotes the manufacturer's profit demand per unit time. Therefore, we need to optimize the EW strategy to reduce 


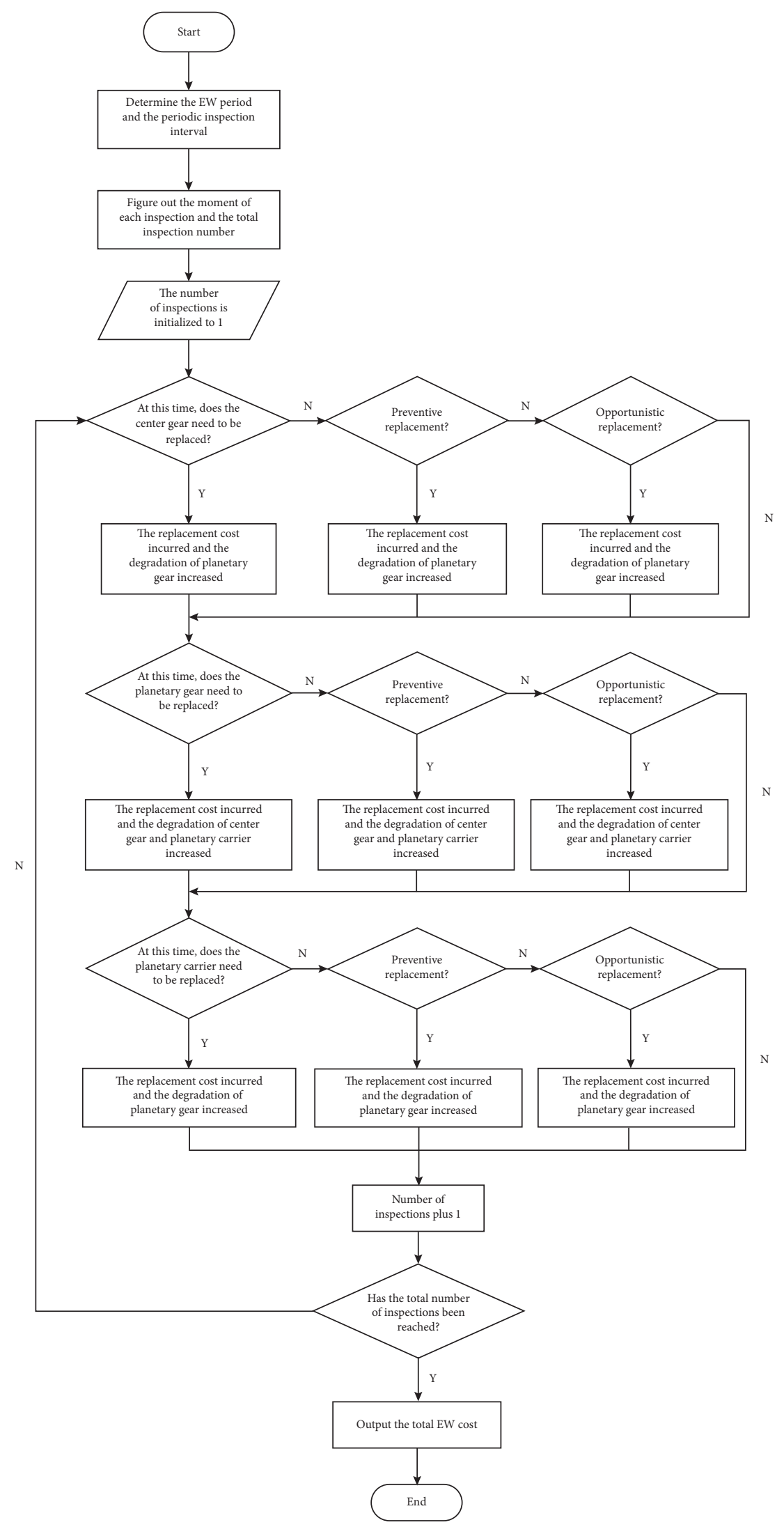

FIGURE 8: The flowchart of Monte Carlo simulation. 


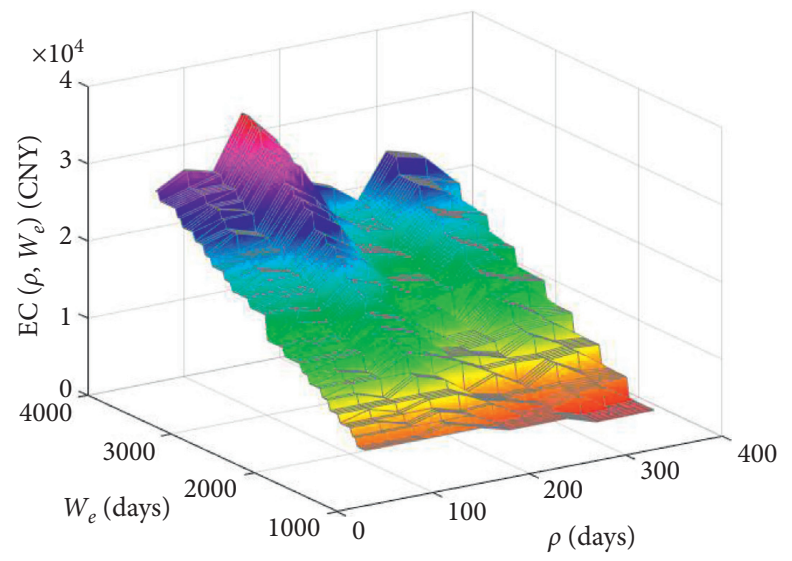

FIgURE 9: Change trend of system EW cost with different EW periods and inspection intervals.

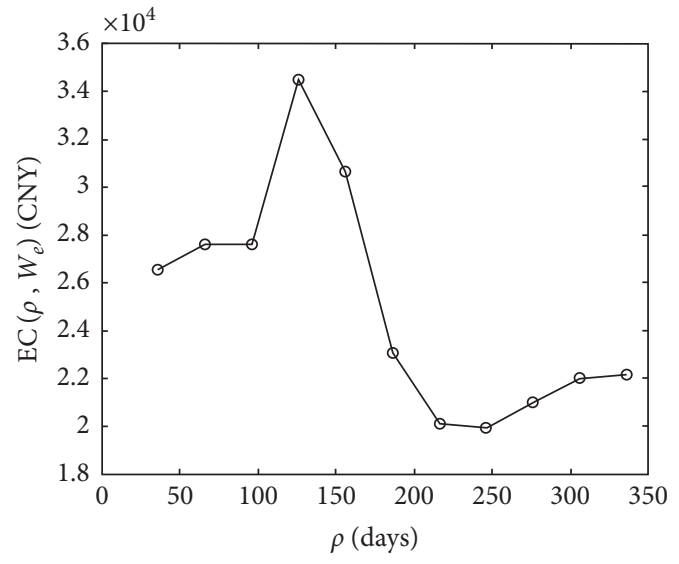

(a)

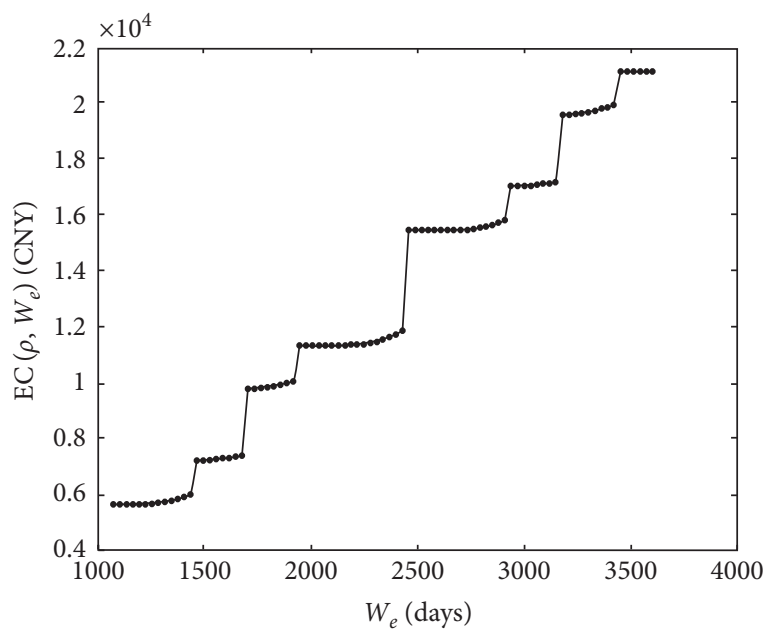

(c)

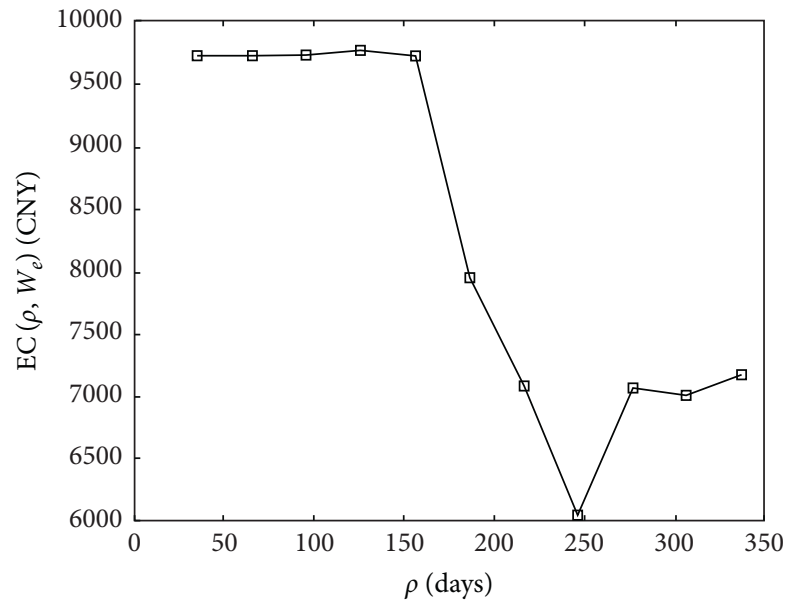

(b)

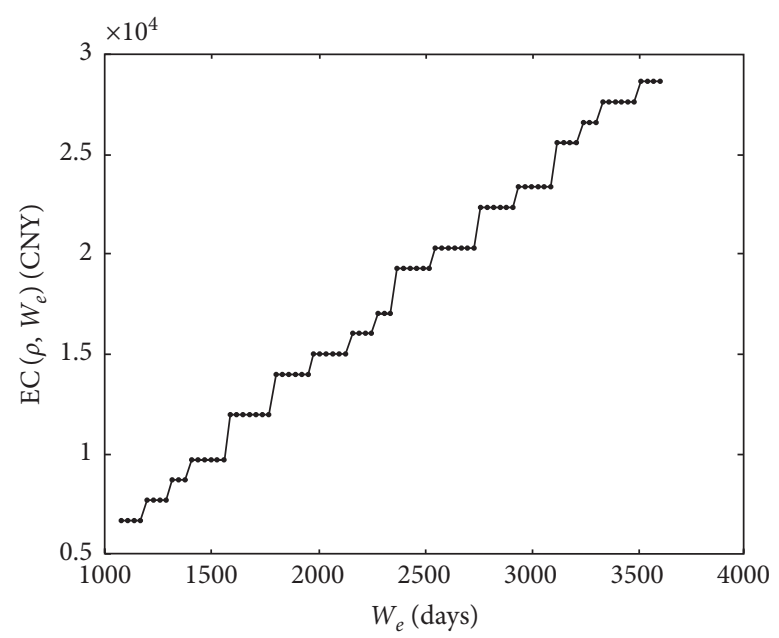

(d)

FIGURE 10: The dimensionality reduction analysis chart of the system EW cost. (a) $W_{e}=3420$ days. (b) $W_{e}=1440$ days. (c) $\rho=246$ days. (d) $\rho=96$ days.

EW cost and then to reduce the EW price. Supposing that the profit demand per unit time of the manufacturer for the planetary gear train is $\psi=2000 \mathrm{CNY}$ per year, then, based on the above data and combined with the EW price model, the decision results of EW price from plan 1 to plan 15 are shown in Table 3. 
TABLE 3: Optimization plans corresponding to different EW periods.

\begin{tabular}{lcccc}
\hline Plan & $W_{e}($ days $)$ & $\rho^{*}($ days $)$ & $\mathrm{EC}\left(\rho^{*}, W_{e}\right)(\mathrm{CNY})$ & $P\left(\rho^{*}, W_{e}\right)(\mathrm{CNY})$ \\
\hline 1 & 1080 & 276 & 4488.80 & 6488.80 \\
2 & 1260 & 276 & 4528.05 & 7528.05 \\
3 & 1440 & 246 & 6043.02 & 10043.02 \\
4 & 1620 & 336 & 7234.22 & 12234.22 \\
5 & 1800 & 276 & 9650.16 & 15650.16 \\
6 & 1980 & 336 & 9725.58 & 16725.58 \\
7 & 2160 & 216 & 11077.76 & 19077.76 \\
8 & 2340 & 336 & 12283.76 & 21283.76 \\
9 & 2520 & 336 & 14693.97 & 24693.97 \\
10 & 2700 & 336 & 14758.10 & 25758.10 \\
11 & 2880 & 246 & 15700.43 & 27700.43 \\
12 & 3060 & 246 & 17070.65 & 30070.65 \\
13 & 3240 & 246 & 19581.58 & 33581.58 \\
14 & 3420 & 246 & 19922.86 & 34922.86 \\
15 & 3600 & 246 & 21128.34 & 37128.34 \\
\hline
\end{tabular}

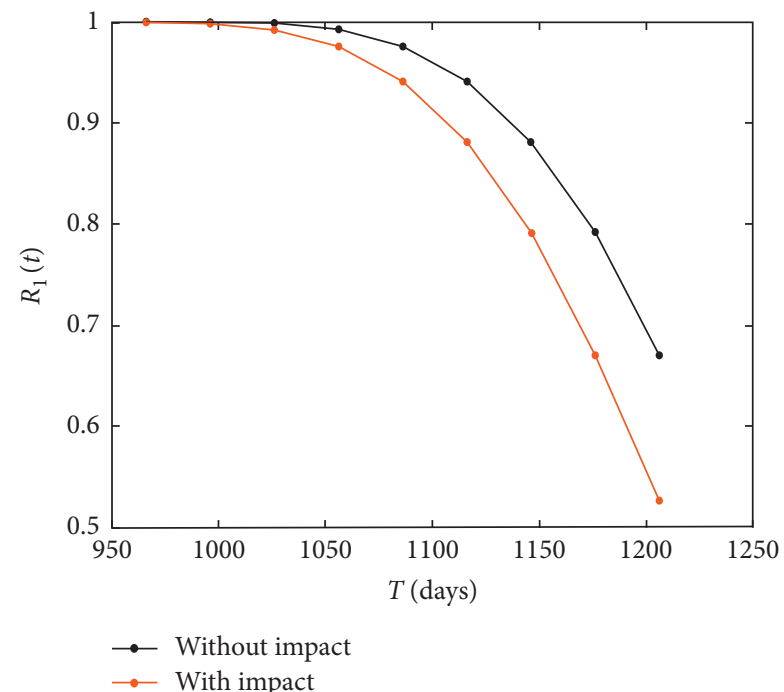

(a)

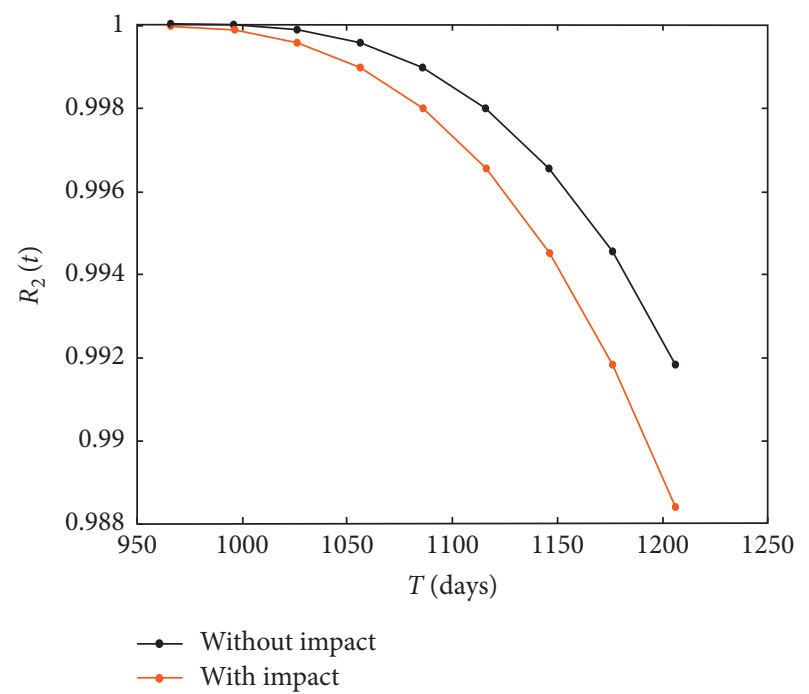

(b)

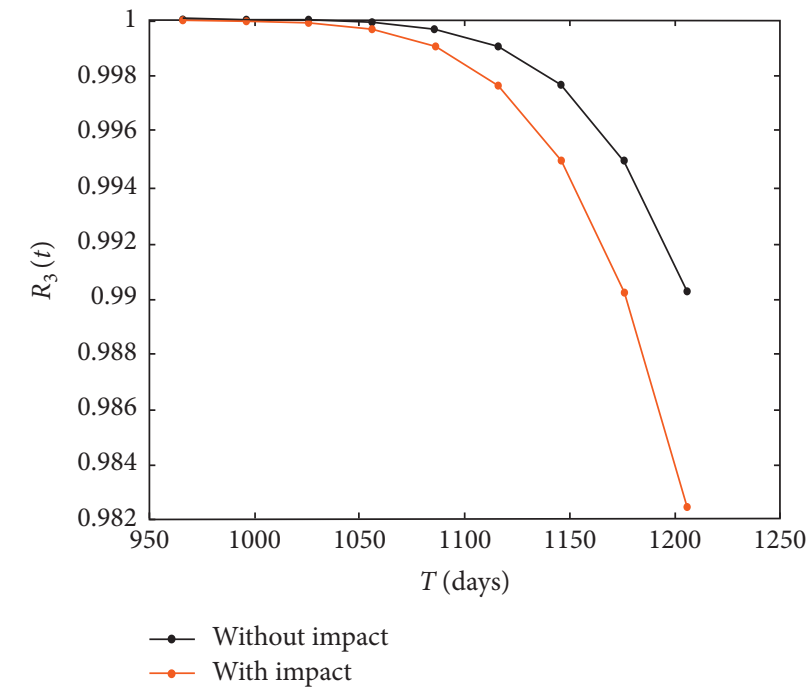

(c)

FIgURe 11: Component reliability with the disassembly operation impact. (a) The reliability of center gear. (b) The reliability of planetary gear. (c) The reliability of planetary carrier. 


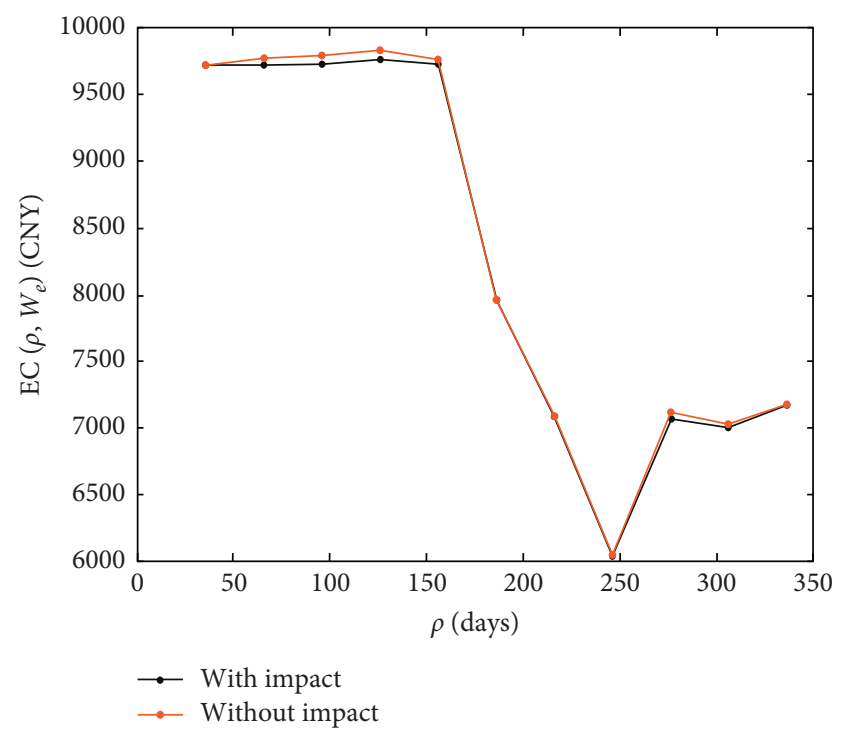

(a)

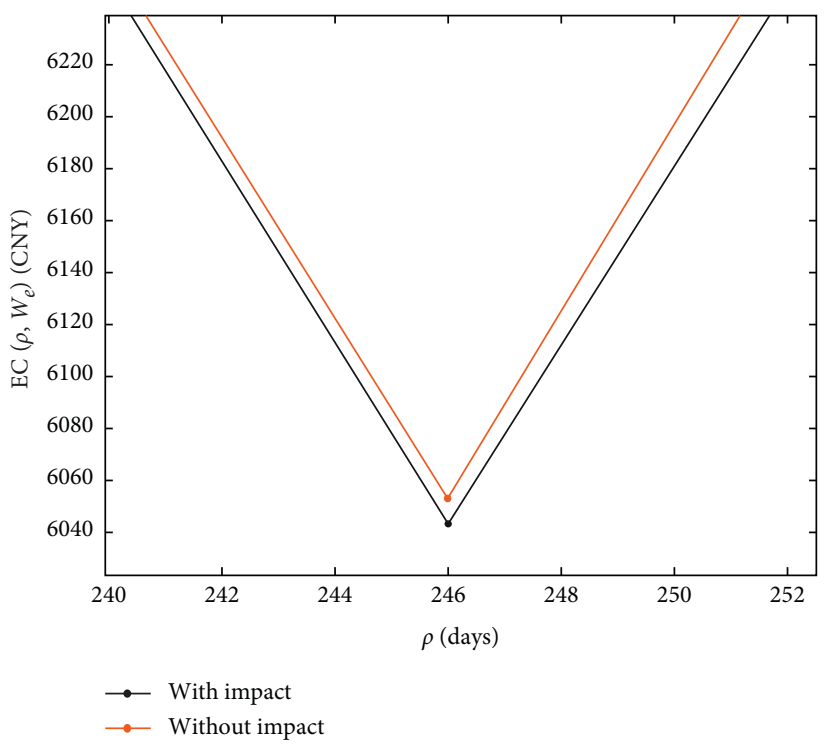

(b)

Figure 12: (a) The comparison of the above two situations. (b) Partial enlarged view of the lowest EW cost.

It can be seen from Table 3, by optimizing the periodic inspection interval, we can obtain the optimal EW cost and EW price under different EW periods. The data in Table 3 can provide a scientific and reasonable basis to determine the EW price of the planetary gear train. On the basis of the above analysis and plans in Table 3, some specific proposals for manufacturers and consumers can be obtained. For one thing, when manufacturers are doing marketing management, they can reduce the EW price as much as possible under the guarantee of their own profit demand, thereby increasing users' enthusiasm for buying EW and expanding the market share. For another thing, users can selectively purchase EW in customization and combine their own demands to reduce the product utilization cost.

4.3. Reliability Assessment with the Disassembly Operation Impact. In this section, the impact of disassembly operations on the component reliability will be investigated. It is assumed that $W_{e}=1440$ days, so the optimal periodic inspection $\rho^{*}=246$ days. Then, according to the above calculation and analysis, we can know all the maintenance activities and maintenance moments of each component during the EW period. Supposing that at the inspection $T_{v}$, the planetary gear, center gear, and planetary carrier are replaced. Based on equations (18) and (19), Figure 11 shows the predicted reliability of the three components at the next inspection $T_{v+1}$. It underlines that the disassembly operations have a significant impact on component reliability.

\subsection{Analysis of Disassembly Operation Impact on the Optimal} Maintenance Strategy. To illustrate the impact of disassembly operation on the optimal maintenance strategy, it is assumed that the impact of disassembly operation on the failure rate of the component is ignored, that is, the value of $L_{i Q^{h}}$ is 0 in the degradation function presented in equation
(14). In the meantime, for the convenience of analysis and comparison, we take $W_{e}=1440$ days as an example, then the optimal periodic inspection interval $\rho^{*}=246$ days. Then, these values are next applied to the system to analyze the impact of disassembly operation. Consequently, we only need to add the minimal maintenance cost due to disassembly operations and the lowest system EW cost is now 6052.76 CNY. This is significantly higher than the EW cost determined in Section $4.2(0.16 \%$ increase). The reason is that in Section 4.2, the impact of disassembly operation is integrated in the optimization process to find the optimal EW cost, while this is not the case in Section 4.3 (the impact is considered after calculation of the optimal parameters). It implies that not regarding structural dependence between components in finding the optimal decision variables can lead to a suboptimal maintenance policy. The comparison of the above two situations is shown in Figure 12.

It should be noted that if the impact of disassembly operations is not considered in the whole modeling process, the EW cost will certainly be lower because the increase of failure rate caused by disassembly operation due to structural dependence is not considered.

\section{Conclusions and Future Research Directions}

In this paper, we investigate the CBM strategy with a periodic inspection interval for the multi-component system with structural dependence under extended warranty, taking into account the impact of disassembly operation on the failure rate of the system due to the structural dependence. Several factors that influence the impact of disassembly operation have been considered and modeled. For this purpose, a Weibull proportional hazard model that combines the degradation function and failure rate is employed to construct the failure rate function of the components. Then, the disassembly operation is described and the 
disassembly operation impact is modeled to develop the failure rate model considering the impact of disassembly operation under EW. This study also proposed the preventive replacement and opportunistic preventive replacement strategy in order to better fit the actual situation where the overall trend of component failure rate is rising. The presented model is finally applied for maintenance cost optimization of the planetary gear train of an automobile generator. By optimizing the EW cost, the optimal inspection interval and the lowest EW cost corresponding to different EW periods can be obtained. It can be concluded from the numerical example that the maintenance plan and EW cost will be suboptimal if the impact of disassembly operations is ignored. In the future, we think that it is a very valuable research direction to consider the impact of disassembly operation on degradation parameters, which will have a certain impact on maintenance decision modeling and engineering applications.

\section{Data Availability}

All data, models, and codes generated or used during the study are included within the article.

\section{Conflicts of Interest}

The authors declare that they have no conflicts of interest.

\section{Acknowledgments}

This research work was financially supported by the National Natural Science Foundation of China (no. 71871219).

\section{References}

[1] B. Liu, L. Shen, J. Xu, and X. Zhao, "A complimentary extended warranty: profit analysis and pricing strategy," International Journal of Production Economics, vol. 229, Article ID 107860, 2020.

[2] C.-W. Yeh and C.-C. Fang, "Optimal pro-rata warranty decision with consideration of the marketing strategy under insufficient historical reliability data," The International Journal of Advanced Manufacturing Technology, vol. 71, no. 912, pp. 1757-1772, 2014.

[3] W. R. Blischke and D. N. P. Murthy, "Product warranty management - I: a taxonomy for warranty policies," European Journal of Operational Research, vol. 62, no. 2, pp. 127-148, 1992.

[4] S. He, Z. Zhang, G. Zhang, and Z. He, "Two-dimensional base warranty design based on a new demand function considering heterogeneous usage rate," International Journal of Production Research, vol. 55, no. 23, pp. 7058-7072, 2017.

[5] Z.-S. Ye and D. N. P. Murthy, "Warranty menu design for a two-dimensional warranty," Reliability Engineering \& System Safety, vol. 155, pp. 21-29, 2016.

[6] Y.-S. Huang, C.-D. Huang, and J.-W. Ho, "A customized twodimensional extended warranty with preventive maintenance," European Journal of Operational Research, vol. 257, no. 3, pp. 971-978, 2017.

[7] R. Zheng and C. Su, "A flexible two-dimensional basic warranty policy with two continuous warranty regions,"
Quality and Reliability Engineering International, vol. 36, no. 6, pp. 2003-2018, 2020.

[8] Z. He, D. Wang, S. He, Y. Zhang, and A. Dai, "Two-dimensional extended warranty strategy including maintenance level and purchase time: a win-win perspective," Computers and Industrial Engineering, vol. 141, Article ID 106294, 2020.

[9] J. C. Hartman and K. Laksana, "Designing and pricing menus of extended warranty contracts," Naval Research Logistics (NRL), vol. 56, no. 3, pp. 199-214, 2009.

[10] C. Su and J. Shen, "Analysis of extended warranty policies with different repair options," Engineering Failure Analysis, vol. 25, pp. 49-62, 2012.

[11] K. Shahanaghi, R. Noorossana, S. G. Jalali-Naini, and M. Heydari, "Failure modeling and optimizing preventive maintenance strategy during two-dimensional extended warranty contracts," Engineering Failure Analysis, vol. 28, pp. 90-102, 2013.

[12] D. N. P. Murthy and N. Jack, Extended Warranties, Maintenance Service and Lease Contracts: Modeling and Analysis for Decision-Making, Springer, London, UK,, 2014.

[13] D. N. P. Murthy and I. Djamaludin, "New product warranty: a literature review," International Journal of Production Economics, vol. 79, no. 3, pp. 231-260, 2002.

[14] N. A. Lutz and V. Padmanabhan, "Warranties, extended warranties, and product quality," International Journal of Industrial Organization, vol. 16, no. 4, pp. 463-493, 1998.

[15] X. Wang and Z.-S. Ye, "Design of customized two-dimensional extended warranties considering use rate and heterogeneity," IISE Transactions, vol. 53, no. 3, pp. 341-351, 2020.

[16] C. Su and X. Wang, "A two-stage preventive maintenance optimization model incorporating two-dimensional extended warranty," Reliability Engineering and System Safety, vol. 155, pp. 169-178, 2016.

[17] P. Tong, Z. Liu, F. Men, and L. Cao, "Designing and pricing of two-dimensional extended warranty contracts based on usage rate," International Journal of Production Research, vol. 52, no. 21, pp. 6362-6380, 2014.

[18] X. Zhao and M. Xie, "Using accelerated life tests data to predict warranty cost under imperfect repair," Computers and Industrial Engineering, vol. 107, pp. 223-234, 2017.

[19] D. H. Dinh, P. Do, and B. Iung, "Degradation modeling and reliability assessment for a multi-component system with structural dependence," Computers and Industrial Engineering, vol. 144, Article ID 106443, 2020.

[20] M. Colledani, T. Tolio, A. Fischer et al., "Design and management of manufacturing systems for production quality," CIRP Annals, vol. 63, no. 2, pp. 773-796, 2014.

[21] P. Do, H. C. Vu, A. Barros, and C. Bérenguer, "Maintenance grouping for multi-component systems with availability constraints and limited maintenance teams," Reliability Engineering and System Safety, vol. 142, pp. 56-67, 2015.

[22] B. Iung, P. Do, E. Levrat, and A. Voisin, "Opportunistic maintenance based on multi-dependent components of manufacturing system," CIRP Annals, vol. 65, no. 1, pp. 401-404, 2016.

[23] D.-H. Dinh, P. Do, and B. Iung, "Maintenance optimisation for multi-component system with structural dependence: application to machine tool sub-system," CIRP Annals, vol. 69, no. 1, pp. 417-420, 2020.

[24] L. C. Thomas, "A survey of maintenance and replacement models for maintainability and reliability of multi-item systems," Reliability Engineering, vol. 16, no. 4, pp. 297-309, 1986. 
[25] N. Chalabi, M. Dahane, B. Beldjilali, and A. Neki, "Optimisation of preventive maintenance grouping strategy for multicomponent series systems: particle swarm based approach," Computers and Industrial Engineering, vol. 102, pp. 440-451, 2016.

[26] P. Do, R. Assaf, P. Scarf, and B. Iung, "Modelling and application of condition-based maintenance for a two-component system with stochastic and economic dependencies," Reliability Engineering and System Safety, vol. 182, pp. 86-97, 2019.

[27] M. C. A. Olde Keizer, S. D. P. Flapper, and R. H. Teunter, "Condition-based maintenance policies for systems with multiple dependent components: a review," European Journal of Operational Research, vol. 261, no. 2, pp. 405-420, 2017.

[28] J. H. Cha, M. Finkelstein, and G. Levitin, "On preventive maintenance of systems with lifetimes dependent on a random shock process," Reliability Engineering and System Safety, vol. 168, pp. 90-97, 2017.

[29] X. Zhao, K. N. Al-Khalifa, A. Magid Hamouda, and T. Nakagawa, "Age replacement models: a summary with new perspectives and methods," Reliability Engineering and System Safety, vol. 161, pp. 95-105, 2017.

[30] C. D. Dao and M. J. Zuo, "Selective maintenance of multi-state systems with structural dependence," Reliability Engineering and System Safety, vol. 159, pp. 184-195, 2017.

[31] Z. Zhu and Y. Xiang, "Condition-based maintenance for multi-component systems: modeling, structural properties, and algorithms," IISE Transactions, vol. 53, no. 1, pp. 88-100, 2021.

[32] S. Alaswad and Y. Xiang, "A review on condition-based maintenance optimization models for stochastically deteriorating system," Reliability Engineering and System Safety, vol. 157, pp. 54-63, 2017.

[33] S. H. Ding and S. Kamaruddin, "Maintenance policy optimization-literature review and directions," The International Journal of Advanced Manufacturing Technology, vol. 76, no. 5-8, pp. 1263-1283, 2015.

[34] R. Dekker, R. E. Wildeman, and F. A. Van Der Duyn Schouten, "A review of multi-component maintenance models with economic dependence," Mathematical Methods of Operations Research, vol. 45, no. 3, pp. 411-435, 1997.

[35] Z. Tian and H. Liao, "Condition based maintenance optimization for multi-component systems using proportional hazards model," Reliability Engineering and System Safety, vol. 96, no. 5, pp. 581-589, 2011.

[36] R. Ahmad and S. Kamaruddin, "An overview of time-based and condition-based maintenance in industrial application," Computers and Industrial Engineering, vol. 63, no. 1, pp. 135-149, 2012.

[37] A. Alrabghi, "Modelling condition-based maintenance for nonidentical two-component systems considering four types of dependencies," Journal of Quality in Maintenance Engineering, vol. 27, no. 1, pp. 169-186, 2021.

[38] X. Zhou, K. Huang, L. Xi, and J. Lee, "Preventive maintenance modeling for multi-component systems with considering stochastic failures and disassembly sequence," Reliability Engineering and System Safety, vol. 142, pp. 231-237, 2015.

[39] J. Hu and P. Chen, "Predictive maintenance of systems subject to hard failure based on proportional hazards model," Reliability Engineering and System Safety, vol. 196, Article ID 106707, 2020.

[40] Z. Zhou, G. Dai, X. Zhang, C. Hu, and Y. Zhang, "Research of partial destructive based selective disassembly sequence planning," The Open Mechanical Engineering Journal, vol. 9, pp. 605-612, 2015.

[41] A. J. D. Lambert, "Disassembly sequencing: a survey," International Journal of Production Research, vol. 41, no. 16, pp. 3721-3759, 2003.

[42] M. Kheder, M. Trigui, and N. Aifaoui, "Optimization of disassembly sequence planning for preventive maintenance," The International Journal of Advanced Manufacturing Technology, vol. 90, no. 5-8, pp. 1337-1349, 2017.

[43] P. Pyy, "An analysis of maintenance failures at a nuclear power plant," Reliability Engineering and System Safety, vol. 72, no. 3, pp. 293-302, 2001.

[44] Z. Zhao, B. Xiao, N. Wang, X. Yan, and L. Ma, "Selective maintenance optimization for a multi-state system considering human reliability," Symmetry-Basel, vol. 11, no. 5, 2019.

[45] J. M. Thompson and M. K. Thompson, "A proposal for the calculation of wear," in Proceedings of the 2006 International ANSYS Users Conference \& Exhibition, Pittsburgh, PA, USA, January 2006. 